\title{
Recursive Water Balloon Drop: A Design Process Exercise
}

\section{Prof. Nathan Delson, University of California, San Diego}

Nathan Delson, Ph.D. is a Teaching Professor at the University of California at San Diego. His interests include robotics, biomedical devices, product design, and engineering education. He is co-founder of Coactive Drive Corporation, a company that provides force feedback solutions. Since 1999 he has taught engineering design and been the director of the Mechanical Engineering Design center at UC San Diego. In fall 2012, Dr. Delson introduced a Product Design \& Entrepreneurship course, where students develop their own product concepts. 


\title{
Recursive Water Balloon Drop: A Design Process Exercise
}

\author{
Nathan Delson, Raymond de Callafon, and David Evers \\ University of California at San Diego, Dept. of Mechanical and Aerospace Engineering
}

\begin{abstract}
An classroom exercise was developed to improve upon a popular egg drop exercise, where students build a packaging container to protect a raw egg and then see which design can be dropped from the highest height without the egg breaking. The "Recursive Water Balloon Drop" substituted a water balloon for the egg so that each team could experiment with multiple balloon drops. In addition a high speed video was taken of the impact of the structure and the balloon hitting the ground. The purpose of these modifications was to develop skill in management of the iterative nature of the design process and to use data to guide design improvement. Another aspect of the exercise was an individual concept generation phase before the team worked together to help generate a wide range of design concepts and prevent personality from dominating concept generation. Documentation was included before and after each drop to compare hypotheses to actual performance. The project was implemented with 23 students working in 6 teams, and took 3 hours of class time for the hardware portion of the project. After the water balloon project, the same teams worked on a larger 80 hour deign project carried out over 3 weeks. At the end of class a survey was administered which asked how the water balloon exercise impacted effectiveness in the larger design project. The largest impact was in increasing effectiveness in the Design Process with 57\% indicating a significant help, and an additional 23\% indicated is as somewhat helpful. Increased Teamwork effectiveness was rated by $52 \%$ as significant and 39\% as somewhat significant. Increase in Creativity was rated by $39 \%$ as significant and $44 \%$ as somewhat significant. Increase in Applying Physics was rated by $26 \%$ as significant and $30 \%$ as somewhat significant. Overall, the Recursive Water Balloon Drop project was of sufficient duration and intensity that it allowed learning to occur in the areas of teamwork and the design process.
\end{abstract}

\section{Background}

Use of games in the classroom is an accepted pedagogical method, with many examples being in business and management education ${ }^{1}$. Games are also used in engineering education, often with an emphasis of improving teamwork, along with creativity, and are also used as an ice breaker ${ }^{2}$. Students generally enjoy these games, but they do take class time, material resources, and teacher effort. Therefore it is essential that games are structured to reach desired context and that the effectiveness of the learning is assessed. Studies have been done regarding the effectiveness of games as a teaching method in business education ${ }^{3}$, but much less has been done in this area for engineering. Verzat et. al. ${ }^{2}$ implemented an engineering design class the challenge of building structures from spaghetti and thread with the explicit goal of improving team performance and creativity in a following larger team design project. The spaghetti challenge consisted of two 45 minute 
building sessions with a 30 minute group debriefing period between the build sessions. The debriefing session was implemented to improve teamwork performance in the second build session, and provide for more effective learning. Interviews were conducted with students 3 months after the spaghetti project, when the students were participating in their larger design project. Student comments indicated that they enjoyed the game and that the experience emphasized listening to teammate ideas and careful consideration of all design options presented. The student comments presented were antidotal with few statistical results were presented. This paper describes a similar effort to use games in engineering design with explicit educational objectives. In addition to improving teamwork, the objectives presented here included use of instrumentation tools in design iterations and increased creativity and concept generation. In addition, statistical analysis was performed to provide a more quantitative assessment of the learning effectiveness.

The specific design challenged described in this paper was inspired by the egg drop challenge which is used in business, science, and engineering education. In the traditional egg drop challenge students are provided with limited materials and challenged with the objective of building a device that will prevent the egg from breaking during a drop from various heights. A wide range of variations of the egg drop has been implemented. Hoffman ${ }^{4}$ implemented the egg drop in a 30 minute surprise challenge in a management class. Halada ${ }^{5}$ implemented a pendulum impact tester so that an egg contest could be implemented inside during inclement weather (this approach precludes the use of parachutes, which is a "hidden" creative breakthrough in some contests). Warner6 implements the egg drop exercise in a business class to teach strategy and resource markets. He has student teams bid for various components to build there device, and thus the various teams have different building materials. Dow and Klemmer ${ }^{7}$ used the egg drop challenge to study concept generation and creativity, and illustrated the effectiveness of design iterations and learning from each iteration. Specifically they provided a control group with just 1 egg, while a group that was encouraged to iterate was provided a full carton of eggs. This was the only example found of the egg drop challenge with an explicit process of iterative design; understandably so due to the mess involved of many broken eggs. In addition, no cases were found where instrumentation was used to identify causes of failure in an egg drop project and used to improve the design iteration. Hamon et. al. ${ }^{8}$ evaluated the effectiveness of physical prototyping vs. simulation for a 4 bar linkage challenge, but this type of assessment has been lacking with projects similar to the egg drop exercise.

This paper presents a classroom design exercise that extends the egg drop concept into a format more suitable for multiple design iterations. In addition, instrumentation is used to encourage students to apply analysis to their design iterations. To improve teamwork an individual concept generation assignment is completed before the first team meeting. The effectiveness of these various components are assessed in terms of their impact on a following more substantial design project. 


\section{Recursive Water Balloon Drop Exercise}

The "Recursive Water Balloon Drop" exercise was developed to teach students how to manage an iterative design process and use instrumentation tools to improve the design during each iteration. Other educational objectives include developing effective skills in creativity, teamwork, and communication. This project replaced a 15 minute tower building project with cookies. While the cookie tower contest was fun and served as an ice breaker, the teacher consensus was that it did not teach significant teamwork skills or how to manage the iterative nature of the design process. The 15 minute tower project did not have enough time or importance to the students for team issues to arise, or to have a systematic design process.

In Recursive Water Balloon Drop exercise each team of students is provided with water balloons that have been filled with the same amount of water (a water balloon pump was used for this purpose, where the number of pumps used to fill the balloons was the same for each balloon). The kit parts include drinking straws, tape, rubber bands, and nuts and blots. The specific constraints of the challenge are described in more detail in a following section. To improve teamwork a step was added to prevent some students form dominating the team conversation and concept generation. This step was to assign a homework assignment 3 days before the contest, where students individually develop 3 design concepts. In class students gathered in teams to review the concepts and select an initial one to pursue. The purpose of assigning an individual concept generation assignment before the teamwork was to encourage concept contributions by all team members and have an explicit phase in the projects where all students had a chance to voice their concepts while others had an active listening portion.

Before dropping the balloons each team documented their hypothesis as to what will cause the balloon to eventually break as the drop height increased. The students then dropped their packages at increasing height until the balloon bursts. During each drop the event was recorded with a high speed camera. We used a Casio EX that could shoot at 1200 frames per second (fps), but with incorporation of high speed photography into smartphones at up to $240 \mathrm{fps}$, the use of high speed photography for classroom exercises is becoming increasing accessible. After each drop the students were instructed to evaluate their video footage and document what caused their balloon to burst. Students were provided with 3 hours of class time for the hands-on portion of the project which included the team meetings and documentation.

The objective of the Recursive Water Balloon Drop exercise is to improve student effectiveness in managing the iterative nature of the design process, concept generation, communication within a team, use of instrumentation tools, and teamwork. Following the Recursive Water Balloon Drop, the same teams of students completed an intensive 3 week design project. At the end of this larger project, students were asked how water balloon project impacted their performance in the larger project. 


\section{Implementation}

The Recursive Water Balloon exercise was implemented in the summer of 2014 at the University of California, San Diego. The class was part of the California State Summer School for Mathematics and Science (COSMOS), which is a four-week residential summer program open to high school students. Each student enrolls in a single class, which they take every weekday from $9 \mathrm{am}-4 \mathrm{pm}$. The caliber of the students was quite high, and indeed the curriculum used was similar to that of a freshman level engineering design course. Accordingly, we believe these results are relevant to both high school and college courses.

There were 23 students in the class who were formed into 6 teams. The first week of the class was spent on an individual design project. The water balloon project was implemented at the beginning of the $2^{\text {nd }}$ week, as the first team activity in the class. A key objective of the project was to help students work together as a team, since in the following 3 weeks, the same teams in the water baboon drop continued working together on a more intensive design project. The other objectives included learning about project management, the iterative nature of the design process, incorporating analysis into design, and the documentation. The design challenge was presented as:

Your objective is to drop a water balloon from the highest height without the balloon breaking. You may protect the balloon with the following parts:

- 500 drinking straws.

- A roll of masking tape.

- 5 rubber bands (size 84).

- Nuts and bolts from the left-over bin

The tape and rubber bands may not touch the balloon at the beginning of the drop, but it is ok if during the fall or impact they do come into contact with the balloon. Parts can be cut up, and replacement parts are generally available in a limited amount.

Your protection device including the water balloon may not exceed a starting size of a 10 "x10"x10" cube, but it is ok if the during the drop the device expands. The device must be simply released (no tossing), and cannot hit any structure on the way down. The starting height is defined by the lowest part of the device.

A water balloons filling pump will be used, and a set number of pumps will be given to each balloon, so that all balloons will be filled with a similar amount of water.

Three days before the in-class exercise the students where given the homework assignment, which required each student to independently develop 3 design concepts and sketch them. Communication via annotated sketches is an important design skill. No instruction was provided on sketching, but some general examples were shown. The students took this assignment seriously, and some of the student sketches are shown in Figure 1. 


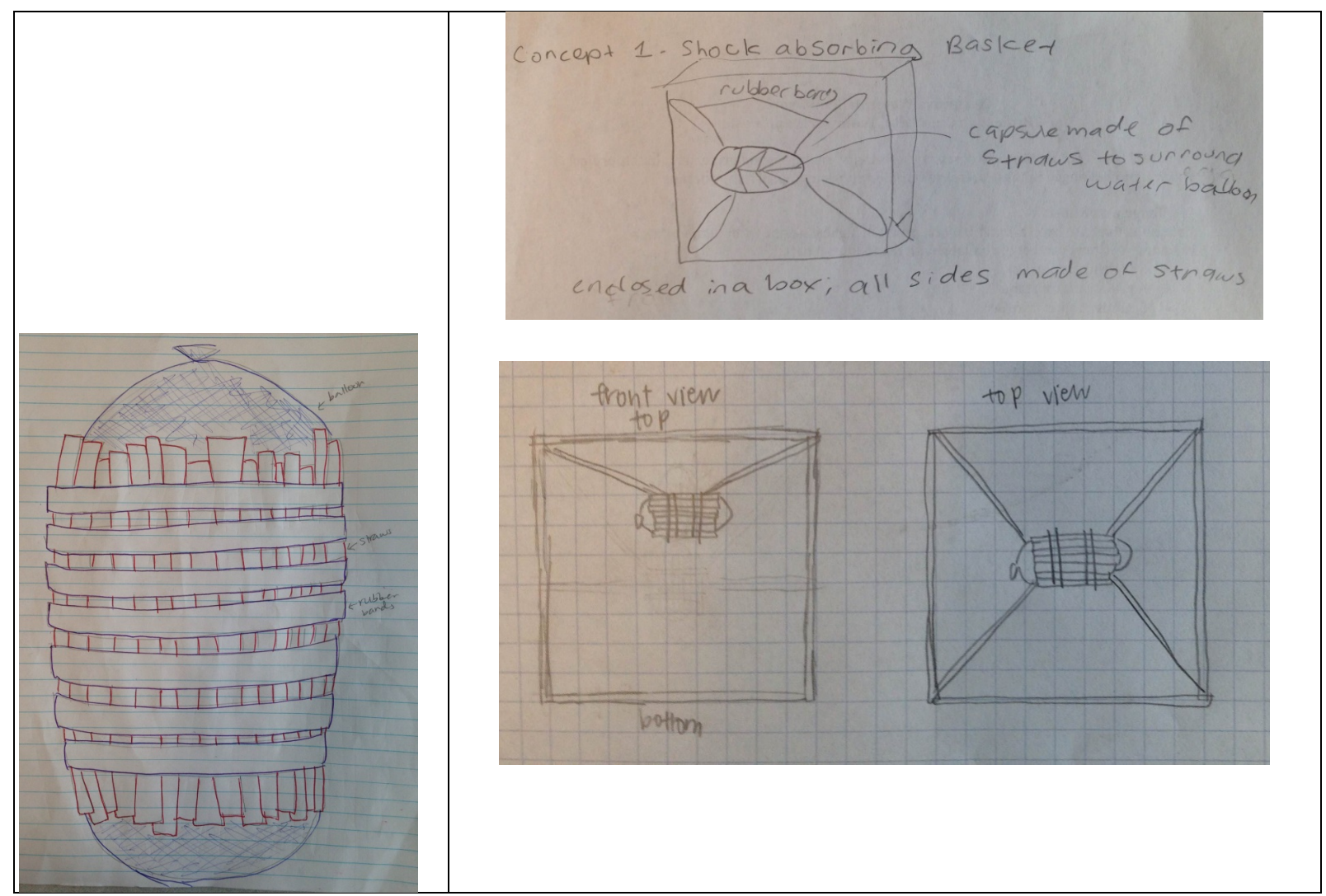

Figure 1. Example Hand Sketches of Various Design Concepts

On the day of the exercise the teams began by having each student present their 3 concepts to the rest of the team and selecting an initial concept to pursue. To implement this step, each team developed a Pugh Chart comparing the various concepts, indicating pros as + and ++ , cons as - and --, and baseline as 0 . Figure 2, shows an example Pugh chart created.

\begin{tabular}{|l|c|c|c|c|c|c|c|c|c|c|c|c|} 
& M1 & M2 & M3 & S1 & S2 & S3 & L1 & L2 & L3 & J1 & J2 & J3 \\
\hline $\begin{array}{l}\text { Ease of } \\
\text { Fabrication }\end{array}$ & - & + & -- & + & - & 0 & + & 0 & + & 0 & + & 0 \\
\hline $\begin{array}{l}\text { High/Low Risk } \\
\text { Amount of }\end{array}$ & ++ & 0 & - & - & + & - & + & 0 & + & -- & 0 & + \\
\hline $\begin{array}{l}\text { Materials } \\
\text { Reusability }\end{array}$ & 0 & - & ++ & + & - & + & + & + & + & + & + & 0 \\
\hline
\end{tabular}

Figure 2. Pugh Chart

The next step was for students to fabricate their designs, some examples of which are shown in Figure 3. 


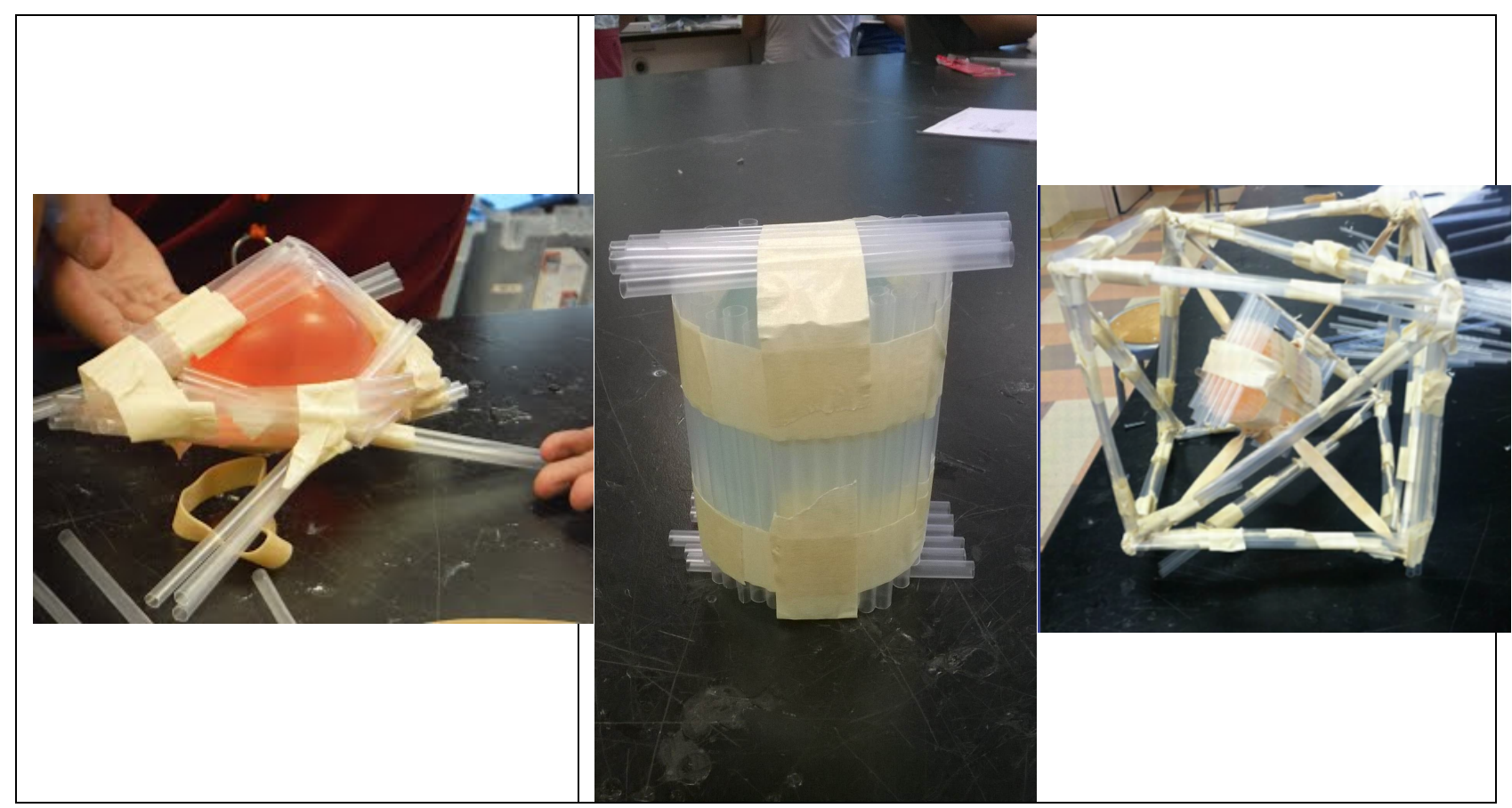

Figure 3. Examples of Initial Structures Built

The actual drop was down from an outdoor stairwell, where the drop height was gradually increased. The high speed camera as mounted on a tripod on the ground to compute the video. Example videos can be seen at (http://maelabs.ucsd.edu/cosmos/teams/index.html). One recommendation coming from this exercise was to use colored water and clear tape in future implementations for better video clarity.

\section{Design Iterations}

Each teams was tasked with performing systematic design iterations. Before each drop each team was tasked with documenting:

- Pre-drop design description including photo, annotations, and expected performance or failure modes.

- Measurement of performance including video clip and written observations.

- Hypotheses regarding reasons for failures and successes.

Off the six groups in the class, only two did a complete analysis of the water balloon drop incorporating both the physical device and video footage. While all groups tested their devices and redesigned them for second and third attempts, it was a little disappointing to see only two groups actually incorporate the video footage into their design recursion process. For instance, the group "Team Six" used the video footage from the first drop to see how the balloon actually broke. One member of Team Six, reflected on this process saying "the high speed camera was extremely useful in the process of designing the structure." His group witnessed the water balloon deform, and then break as it hit the base 
of the device. For the next iteration, the group reinforced the sides in a different manner. They were successful through a six foot drop. Again, when the device failed a second time, they used the footage and made the conclusion that the "cage would only be viable for shorter distances". This led them to the drastic change of adding a parachute. And while a straw parachute seems precarious at best, this did seem to work for them as their device was the only one to survive the drop from the top of the building. Some teams that did not use the high speed video made their hypotheses regarding reasons for balloon burst directly from observation of the physical. These teams opted for faster iteration rather than more in-depth analysis, which could be appropriate in certain situations. In future implementations, we may choose to limit the number of design iterations so that students have more time to investigate failure reasons of each iteration.

The second group that incorporated the video feedback into their design process. A member of this team, shared her thoughts on the design process with an insight into discovered by the high speed camera. She writes:

Being able to view the videos in slow motion helped us see the problems in our design. Seeing other people's designs made me realize that even though the straws can compress and act as a cushion for the water balloons, they were too small to effectively decrease the impulse when the balloon hit the ground. The rubber bands worked a lot better when utilized as shock absorbers.

This observation was only possible due to the use of the high speed camera and the ability to redesign and rebuild the device a second time. Their device's success then hinged on their ability to use the high speed camera as their design shifted into using rubber bands in a new manner.

All 6 teams were highly engaged and performed at least 3 design iterations.

\section{Post Drop Reflections}

Immediately after the water balloon project each team gave an oral presentation to the whole class about their design process. In addition, each student was assigned to write a reflection as a homework assignment that described their experience in the areas of creativity, the scientific method, teamwork, and the design process. Of the 23 students in the class only 16 submitted their reflection write-up. The low response rate was due to the fact that there were no grades in the class, and that the students became busy with following design project. The reflections indicated that overall, the students enjoyed the project and all teams included in their final presentation multiple design iterations that the team implemented. One aspect of the project is that the groups' devices evolved in different manners. All groups utilized each drop as an opportunity to look at the device with the burst balloon to gain a better understanding of why it had failed. Two of the groups went one step farther and incorporated the video recordings in their design process. Of the reflection pieces that we received, most students (14/16) mentioned that they wished they had more time to complete further designs, which is a sign the their high level of engagement with the project. Moreover, roughly half $(7 / 16)$ of the reflections 
described incremental improvement to their original design concept, which is an important part of engineering optimization. Most student reflections mentioned that they should have spent more time on an initial plan, developed their idea more fully before beginning construction, and divided up their workloads in a more efficient manner to have gained better success overall. It is exactly these aspects of the design process that we wish students to internalize. While we present these concepts in lecture, it seems like students have to experience these aspects of the design process directly in order to value their importance. Overall, the students held the project in high regard and felt it was a worthwhile project.

\section{Post Large Project Results}

After completion of the water balloon project the same teams worked on a 3 week design of a kinetic sculpture. This was an intensive effort that was carried out 5 days a week and for 6 hours each day (total of over 80 hours of in-class work). At the conclusion of the complete class a survey was administered that asked how the experience on the water balloon project impacted performance in the larger kinetic sculpture project. The question asked to the students was: Did the Water Balloon project experience increase your effectiveness in the Kinetic Sculpture project in the following area?" The survey results are shown below:

\begin{tabular}{lllllll}
\multicolumn{1}{c}{$\begin{array}{l}\text { Negative } \\
\text { Effect }\end{array}$} & No Effect & $\begin{array}{l}\text { Minimal } \\
\text { Help }\end{array}$ & $\begin{array}{l}\text { Somewhat } \\
\text { Helpful }\end{array}$ & $\begin{array}{l}\text { Significant } \\
\text { Help }\end{array}$ & $\begin{array}{l}\text { No. of } \\
\text { Responses }\end{array}$ \\
$\begin{array}{llll}\text { Creativity } \\
\text { Applying }\end{array}$ & $0.0 \%(0)$ & $4.3 \%(1)$ & $13.0 \%(3)$ & $43.5 \%(10)$ & $39.1 \%(9)$ & 23 \\
$\begin{array}{l}\text { Physics } \\
\text { Teamwork }\end{array}$ & $0.0 \%(0)$ & $17.4 \%(4)$ & $26.1 \%(6)$ & $30.4 \%(7)$ & $26.1 \%(6)$ & 23 \\
$\begin{array}{l}\text { The } \\
\text { Design } \\
\text { Process }\end{array}$ & $0.0 \%(0)$ & $0.0 \%(0)$ & $4.3 \%(1)$ & $39.1 \%(9)$ & $52.2 \%(12)$ & 23 \\
\end{tabular}

The water balloon project was felt to increase effectiveness in all 4 areas. The area deemed to have the most significant help is the Design Process (57\%), with had a combined response of $83 \%$ of either somewhat helpful or significant help. The second most impactful in terms of significant help was teamwork (52\%)area was teamwork, with had a combined response of $91 \%$ of either somewhat helpful or significant help. Creativity had a rating for significant help of 39\%, with a combined response of $83 \%$ of either somewhat helpful or significant help. It is not surprising that applying physics had the lowest rate considering that many teams did not fully exploit the high speed camera, but still $26 \%$ indicated that the experience provided significant help in this area, with a combined response of $57 \%$ of either somewhat helpful or significant help. Overall this survey indicates that the students felt the water balloon project had a large impact on their following design project, which was exactly the objective of the exercise.

\section{Conclusions}

A new hands-on design exercise is presented which is a modification of the traditional egg drop exercise. This new "Recursive Water Balloon Drop" took 3 hours of class time, with an 
additional pre and post homework assignments. This new assignment replaced a 15 minute tower building exercise, but it had significant advantages. The objectives of this new exercise were to develop skills in teamwork, concept generation and selection, management of an iterative design process, incorporation of performance data into the development of new designs, and documentation of the design process.

The effectiveness of the water balloon exercise was assessed by surveying students after their completion of a 3 week team design project. In addition, student reflections and oral presentations immediately after the project were reviewed. A key result was that students took the water balloon challenge seriously. A recurring theme was that students wanted more time to work on the project, and the oral presentations and student sketches all illustrate a high level of commitment to the project. This was a higher level of intensity and involvement than was seen in the 15 minute tower building project, and allowed for more real team issues and design challenges to appear. Comments from students indicated that they indeed gained valuable lessons on the importance of early design decisions, analysis, time management, and effective delegation among team members. The fact that a single day exercise could have a significant impact on a following 3 week project was not a foregone conclusion. Thus, we were especially pleased to see that students saw a somewhat or significant increase in effectiveness in Creativity (83\%), Applying Physics (57\%), Teamwork (91\%), and The Design Process (83\%).

Our goal was to tailor a hands-on classroom exercise to teach specific messages related to the design process. Another example of such an effort includes, Verzat et. al. ${ }^{2}$ who added a debriefing session into a classroom building exercise specifically to improve teamwork. An analogous component of our approach was to have each student develop multiple design concepts before the students got together as a team. This approach was aimed to show that indeed a wide range of design concepts can be developed, and prevent one early design from precluding other designs to be proposed.

Another unique aspect of the water balloon project was this used of instrumentation to guide students in their iterative designs. The exercise used of high speed photography of the impact with the ground when the water balloon burst. Only 2 of the 6 teams used detailed review of the high speed video, while the other teams relies on physical analysis of the structure after impact. In future implementations we propose using colored water in the balloons and clear tape to make the videos more useful.

In addition many specific design process skills were taught including sketching, Pugh Chart construction, and documentation of the design process. The experience also taught time management and decision making under pressure.

A limitation of the study is that the benefits of the study are self-reported by the students in a survey form and self reflection. In the future it would beneficial to tie in specific issues learned in the exercise to specific performance in the follow on project. In addition, it may be possible in the future to preform both the 15 minute tower building project early in the class, and then the water balloon project a bit later. Comparisons of these 2 projects would be useful in identifying the costs and benefits of different duration projects. 


\section{References}

1. Benek-Rivera, J., and Mathews, V. Active learning with Jeopardy: Students ask the questions. Journal of Management Education, 28.1 (2004): 104-118.

2. Verzat, Caroline, Janice Byrne, and Alain Fayolle. "Tangling with spaghetti: Pedagogical lessons from games." Academy of Management Learning \& Education 8.3 (2009): 356-369.

3. Azriel, Jay A., Margaret J. Erthal, and Ervin Starr. "Answers, questions, and deceptions: What is the role of games in business education?." Journal of Education for Business 81.1 (2005): 9-13.

4. Hoffman, C. (2000). Profile: Emphasis on fairness leads to egg-cellence. University of Cincinnati. Retrieved from http:/www.uc.edu/profiles/mastersn.htm

5. Halada, Richard. "Rotational collision apparatus for indoor egg drops." The Physics Teacher 41.5 (2003): 305-305.

6. Warner, Alfred G. "An egg-centric approach to teaching strategic types: Adapting a classic exercise." Journal of Management Education 29.4 (2005): 583-592.

7. Dow, Steven P., and Scott R. Klemmer. "The efficacy of prototyping under time constraints." Design Thinking. Springer Berlin Heidelberg, 2011. 111-128.

8. Hamon, C., and M. Dunlap Green. "B., Camburn, B, Crawford, R., Jensen, D., 2014 "Virtual or Physical Prototypes? Development and Testing of a Prototyping Planning Tool"." $121^{\text {st }}$ ASEE Annual Conference \& Exposition, Indianapolis, IN June 15-18, (2014). 